\title{
Durability and Economic Dynamics
}

\author{
Atsuo Utaka* \\ Kyoto University Yoshida-hommachi, Sakyo-ku, Kyoto, Japan \\ E-mail: autaka@mbox.kyoto-inet.or.jp \\ Received August 25, 2011; revised October 3, 2011; accepted October 10, 2011
}

\begin{abstract}
This paper investigates how product's durability affects the dynamic properties of the economy, using a simple overlapping generations model with durable goods. One of the chief characteristics of the durable-goods market is that a sale condition at a certain period affects another period's condition. It is shown that this interaction causes oscillatory equilibria that diverge from the stationary point. Hicks [1] argued that unstable oscillations in the economy lead to endogenous business cycles. This paper's result provides one reason of how unstable oscillations occur from firm's optimizing behavior.
\end{abstract}

Keywords: Oscillatory Equilibria, Durability

\section{Introduction}

This paper investigates how product's durability affects the dynamic properties by using a simple overlapping generations model with a durable-goods monopolist. In the real economy, the market trends of durable goods have a large effect on business cycles. One of the chief characteristics of the durable-goods market is that business conditions at a certain period affect future conditions, which can cause economic fluctuations.

Benhabib and Day [2], Grandmont [3], Farmer [4], and Reichlin [5] analyzed the existence of endogenous cycles in overlapping generations models. Their models are based on the general equilibrium model, and do not consider durable goods. On the other hand, Conlisk et al. [6] and Sobel [7] constructed the durable-goods monopolist model, in which new consumers enter at every period, investigated the dynamics of the durable-goods market. ${ }^{1}$ They mainly investigated the pricing (and sales) strategy that the monopolist uses, as well as its commitment problem. In contrast, this paper focuses on a difference equation concerning the dynamical system of the durable-goods market.

It is assumed that the firm can increase the demand of its product with its marketing strategy. If the firm strives to sell as many products as possible in a certain period, the demand for its products will decline in the following

\footnotetext{
*I would like to thank an anonymous referee for helpful comments. ${ }^{1}$ It is known that interaction between decisions at different periods causes various kinds of time-inconsistency problem. For the survey of durable-goods analyses, see Waldman [13].
}

periods. To maximize its total profits over the long term, the durable-goods producer takes these dynamic interactions into consideration, which affects the dynamic properties of the economy. Consequently, it is shown that there occur oscillatory equilibria that diverge from the stationary point. Hicks [1] considered a simple dynamic model based on "acceleration principle", and argued that in cases where the dynamic system has unstable oscillations, endogenous business cycles occur because of a ceiling caused by full employment and a floor by investment. (For more detailed analyses concerning Hicks' trade cycle model, see Hommes [8,9], Saura et al. [10], Puu [11], and Matsumoto and Szidarovszky [12].) This paper's analysis provides one way of explaining the Hicks' trade cycle from the viewpoint of firm's optimizing behavior.

\section{The Model}

I construct a simple overlapping generations model. There exists a durable-goods monopolist and consumers. The monopolist firm infinitely continues. On the other hand, consumers live two periods. They use either zero or one unit of the durable-goods in each period. Let us define consumers who enter the market at period $t$ as generation $t$ consumers. Namely, in period $t$, there exist generation $t-1$ consumers in their second stage and generation $t$ consumers in their first stage. The population of each generation is $n$.

It is possible for the product to break down. In other words, the durable goods last two periods (only one pe- 
riod) with probability $\delta(1-\delta)$. $^{2}$ The benefits each consumer obtains by using the durable-goods is $u_{i}$ in his $i$-th stage $(i=1,2)$. Without loss of generality, the production cost of the durable-goods is assumed to be zero. The discount factor of both consumers and the producer is $\rho$, and they are risk neutral. The secondhand market does not exist.

It is assumed that the demand of the durable-goods can be increased by the firm's marketing strategy. Let us suppose informative advertising as the marketing strategy. Then, the higher the marketing (advertising) level becomes, the more consumers recognize the existence of the product. Accordingly, the probability that the information on the product reaches each consumer is assumed to be $f\left(M_{t}\right)$, where $M_{t}$ stands for marketing expenditure by the firm. Consumers who recognize the existence of the products decide whether to buy them at the price the monopolist offers.

The shape of $f\left(M_{t}\right)$ is as follows.

\section{Assumption 1}

$f^{\prime}\left(M_{t}\right) \geq 0, f^{\prime \prime}\left(M_{t}\right) \leq 0$ and $f\left(M_{t}\right) \leq 1$ for all $M_{t}$, and $f^{\prime}(\infty)=0$

In addition, it is assumed that

\section{Assumption 2}

$$
\frac{u_{1}}{2-\delta f\left(M_{t-1}\right)-\delta \rho}<u_{2}<\frac{u_{1}}{1-\delta \rho}
$$

for any $M_{t-1}(t=1,2, \cdots, \infty)$

Under this assumption, we obtain the following result.

\section{Lemma}

The monopolist in any period $t$ decides to set a price $p=u_{2}$ on the products, and sells the products to consumers belonging to generations $t$ and $t-1$ (those who did not buy them in period $t-1$ and whose goods were broken down).

\section{Proof}

[See appendix for the detail.]

In other words, the price of the product becomes constant through all periods. Then, the total demand in period $t$ becomes

$$
n\left[\left\{1-\delta f\left(M_{t-1}\right)\right\} f\left(M_{t}\right)+f\left(M_{t}\right)\right] .
$$

\subsection{Marketing Decision}

From now on, let us analyze the monopolist's behavior on the marketing strategy.

First, I analyze the case where $\delta=0$, namely, the products are non-durable-goods. If $2 u_{2}>u_{1}$, it is optimal for the monopolist in each period to sell the products to both generations. Then, the monopolist's problem at any period $t$ is

$$
\underset{M_{t}}{\operatorname{Max}_{t}} 2 n u_{2} \cdot f\left(M_{t}\right)-M_{t}
$$

The first order condition of this problem becomes

$$
2 n u_{2} \cdot f^{\prime}\left(M_{t}\right)-1=0
$$

Then, the marketing (and production) level is constant through all periods. Naturally, oscillatory equilibria never exist.

Next, let us investigate the monopolist's profit-maximizing problem. As shown before, since the price of a product becomes constantly $u_{2}$, the remaining decision by the monopolist is about the marketing level. The problem of the monopolist at period $t$ becomes (see (1a)).

The first order condition of this problem becomes (see (1b)).

In other words, the dynamical system is described by the second order difference equation. Given initial values $M_{0}$ and $M_{1}$, the equilibrium trajectories of this system are determined by (1b).

\subsection{Stationary Equilibrium}

Stationary equilibrium is derived from the following equation.

$$
n u_{2} \cdot f^{\prime}\left(M^{*}\right)\left\{2-\delta(1+\rho) f\left(M^{*}\right)\right\}=1
$$

Let us assume that

$$
n u_{2} \cdot f^{\prime}(0)\{2-(\delta+\rho) f(0)\}>1 .
$$

Then, we obtain the following result.

\section{Theorem 1}

There exists a stationary equilibrium.

Proof

Let us define the function

$$
n u_{2} \cdot f^{\prime}(M)\{2-\delta(1+\rho) f(M)\}
$$

as $A(M)$. Under assumption 1 ,

$$
\begin{gathered}
\operatorname{Max}_{M_{t}, M_{t+1}, \ldots, M_{\infty}} \sum_{j=0}^{\infty} \rho^{j} n u_{2} \cdot\left[\left\{1-\delta f\left(M_{t+j-1}\right)\right\} \times f\left(M_{t+j}\right)+f\left(M_{t+j}\right)\right]-M_{t+j} \\
n u_{2}\left[f^{\prime}\left(M_{t}\right)\left\{2-\delta f\left(M_{t-1}\right)\right\}-\rho \delta f^{\prime}\left(M_{t}\right) \cdot f\left(M_{t+1}\right)\right]-1=0 \Leftrightarrow \rho \delta f\left(M_{t+1}\right)+\frac{1}{n u_{2} \cdot f^{\prime}\left(M_{t}\right)}+\delta f\left(M_{t-1}\right)=2 .
\end{gathered}
$$

\footnotetext{
${ }^{2}$ In this model, repair market is not considered.
} 


$$
A^{\prime}(M)=n u_{2} \cdot\left[f^{\prime \prime}(M)\{2-\delta(1+\rho) f(M)\}-\delta(1+\rho)\left\{f^{\prime}(M)\right\}^{2}\right]<0 .
$$

Therefore, if

$$
A(0)=n u_{2} \cdot f^{\prime}(0)\{2-\delta(1+\rho) f(0)\}>1
$$

(and $\lim _{M \rightarrow \infty} A(M)=0$ ), there exists a value $M^{*}$ that satisfies (2).

\subsection{Existence of Oscillations}

Let us investigate the dynamic properties. I focus on the existence of oscillatory equilibria near the stationary equilibrium. In order to investigate the dynamic properties of the second order (nonlinear) difference equation, we should examine the characteristics of the Jacobian matrix concerning the difference equation, especially the eigenvalues of its matrix. (See Azariadis [14] for instance.)

In this model, the eigenvalues of the Jacobian matrix evaluated at the stationary state become the solution of the following equation;

$$
\begin{aligned}
& \delta \rho f^{\prime}\left(M^{*}\right) \lambda^{2}-\frac{f^{\prime \prime}\left(M^{*}\right)}{n u_{2} \cdot\left\{f^{\prime}\left(M^{*}\right)\right\}^{2}} \lambda+\delta f^{\prime}\left(M^{*}\right)=0 \\
& \Rightarrow \lambda^{2}-\frac{1}{\delta \rho f^{\prime}\left(M^{*}\right)} \cdot \frac{f^{\prime \prime}\left(M^{*}\right)}{n u_{2} \cdot\left\{f^{\prime}\left(M^{*}\right)\right\}^{2}} \lambda+\frac{1}{\rho} \\
& \equiv \lambda^{2}-T \lambda+D=0 .
\end{aligned}
$$

It is known that oscillation occurs if the corresponding eigenvalues are complex conjugates. From (3), the condition under which complex eigenvalues exist becomes

$$
\begin{aligned}
& T^{2}-4 D<0 \\
& \Leftrightarrow \frac{f^{\prime \prime}\left(M^{*}\right)^{2}}{\left\{f^{\prime}\left(M^{*}\right)\right\}^{6}}<4 \delta^{2} \rho\left(n u_{2}\right)^{2} .
\end{aligned}
$$

In cases where oscillatory equilibria exist, the stability of which depends on the value of $D$ in equation (3). Since $D=\frac{1}{\rho}>1$, they diverge from the stationary point.

Let us summarize the above results.

\section{Theorem 2}

If $\frac{f^{\prime \prime}\left(M^{*}\right)^{2}}{\left\{f^{\prime}\left(M^{*}\right)\right\}^{6}}<4 \delta^{2} \rho\left(n u_{2}\right)^{2}$, there occur oscillatory equilibria. They always diverge from the stationary point.

\section{Conclusions}

Under the situation where the firm can increase the de- mand for the products with its marketing strategy, I constructed a simple overlapping generations model with a durable-goods monopolist and examined the monopolist's strategic behavior.

It has been shown that the levels of its sales and marketing activities oscillate. The important point is that demand conditions at different periods affect each other. The durable-goods firm considers this effect in planning its marketing and sales strategy and this behavior causes oscillatory equilibria.

\section{References}

[1] J. R. Hicks, "A Contribution to the Theory of the Trade Cycle,” Clarendon Press, Oxford, 1950.

[2] J. Benhabib and R. H. Day, "A Characterization of Erratic Dynamics in the Overlapping Generations Model," Journal of Economic Dynamics and Control, Vol. 4, No. 1, 1982, pp. 37-55. doi:10.1016/0165-1889(82)90002-1

[3] J. M. Grandmont, “On Endogenous Competitive Business Cycles,” Econometrica, Vol. 53, No. 5, 1985, pp. 9951045. doi:10.2307/1911010

[4] R. E. Farmer, "Deficits and Cycles," Journal of Economic Theory, Vol. 40, No. 1, 1986, pp. 77-88. doi:10.1016/0022-0531(86)90008-6

[5] P. Reichlin, "Equilibrium Cycles in an Overlapping Generations Economy with Production,” Journal of Economic Theory, Vol. 40, No. 1, 1986, pp. 89-102. doi:10.1016/0022-0531(86)90009-8

[6] J. Conlisk, E. Gerstner and J. Sobel, "Cyclic Pricing by a Durable Goods Monopolist," Quarterly Journal of Economics, Vol. 99, No. 3, 1984, pp. 489-505. doi: $10.2307 / 1885961$

[7] J. Sobel, "Durable Goods Monopoly with Entry of New Consumers," Econometrica, Vol. 59, No. 5, 1991, pp. 1455-1485. doi:10.2307/2938375

[8] C. H. Hommes, "Periodic, Almost Periodic and Chaotic Behaviour in Hicks' Non-Linear Trade Cycle Model," Economics Letters, Vol. 41, No. 4, 1993, pp. 391-397. doi:10.1016/0165-1765(93)90211-T

[9] C. H. Hommes, “A Reconsideration of Hicks' Non-Linear Trade Cycle Model,” Structural Change and Economic Dynamics, Vol. 6, No. 4, 1995, pp. 435-459. doi:10.1016/0954-349X(95)00032-I

[10] D. Saura, F. J. Vazquez and J. M. Vegas, "Non-Chaotic Oscillations in Some Regularized Hicks Models," Journal of Economic Dynamics and Control, Vol. 22, No. 5, 1998, pp. 667-678. doi:10.1016/S0165-1889(97)00078-X

[11] T. Puu, "The Hicksian Trade Cycle with Floor and Ceiling Dependent on Capital Stock,” Journal of Economic Dynamics and Control, Vol. 31, No. 2, 2007, pp. 575592. doi:10.1016/j.jedc.2005.12.004

[12] A. Matsumoto and F. Szidarovszky, "Continuous Hick- 
sian Trade Cycle Model with Consumption and Investment Time Delays," Journal of Economic Behavior and Organization, Vol. 75, No. 1, 2010, pp. 95-114. doi:10.1016/j.jebo.2010.03.010

[13] M. Waldman, "Durable Goods Theory for Real World
Markets,” Journal of Economic Perspectives, Vol. 17, No. 1, 2003, pp. 131-154. doi:10.1257/089533003321164985

[14] C. Azariadis, "Intertemporal Macroeconomics,” Blackwell, New York, 1993.

\section{Appendix}

Here, I analyze the price of the durable goods. In any period $t$, the monopolist has two options; to sell the products to both generations $t-1$ and $t$ consumers, or to sell them only to generation $t$ consumers at a higher price.

In the former case, the price of a product should be $p=u_{2}$. It is because generation $t-1$ consumers use the products only during one period, if they buy the product at period $t$. If we describe marketing expenditure in this case as $M^{a}$, total demand in period $t$ becomes

$$
n\left[\left\{1-\delta f\left(M^{a}{ }_{t-1}\right)\right\} f\left(M_{t}^{a}\right)+f\left(M_{t}^{a}\right)\right] .
$$

Therefore, profits of the monopolist in period $t$ are

$$
n u_{2}\left\{2-\delta f\left(M_{t-1}^{a}\right)\right\} f\left(M_{t}^{a}\right)-M_{t}^{a}
$$

In the latter case where the monopolist sells the prod-

ucts only to generation $t$ consumers, the price becomes $p=u_{1}+\delta \rho u_{2}$. (At this price, Generation $t-1$ does not buy the products under assumption 2.) Let us denote marketing expenditure in this case as $M^{y}$. Since the demand in period $t$ is $n f\left(M_{t}^{y}\right)$, profits of the monopolist in period $t$ become

$$
n\left(u_{1}+\delta \rho u_{2}\right) \cdot f\left(M_{t}^{y}\right)-M_{t}^{y}
$$

Under assumption 2, for all $M_{t-1}$,

$$
\begin{aligned}
& u_{2}>\frac{u_{1}}{2-\delta f\left(M_{t-1}\right)-\delta \rho} \\
& \Leftrightarrow u_{2}\left\{2-\delta f\left(M_{t-1}\right)\right\}>u_{1}+\delta \rho u_{2} .
\end{aligned}
$$

Then, it can be easily shown that profits (A1) become larger than (A2) at their maximum levels of $M^{a}{ }_{t}$ and $M^{y}{ }_{t}$. Consequently, it is optimal for the monopolist in period $t$ to sell their products to both generations $t-1$ and $t$ consumers. 